\title{
Earthquake architecture as an expression of a stronger architectural identity in seismic areas
}

\author{
T. Slak \& V. Kilar \\ University of Ljubljana, Faculty of Architecture, Slovenia
}

\begin{abstract}
This paper discusses the term "earthquake architecture" as a result of intersection of design principles in architecture and earthquake engineering. It examines the hypothesis that the architectural design which reflects an earthquake threat might be an important source of stronger architectural identity typical for earthquake prone areas. The purpose of the paper is to encourage the development of new principles and forms of architectural design in these areas. Technology, codes and cooperation with earthquake engineers are not the only or satisfactory solutions for appropriate culturally respectful design of buildings and landscape in earthquake prone areas. The possibilities of architectural response to an earthquake threat are further analyzed. The paper describes earthquake engineering and architectural background of earthquake architecture and gives some examples of positive practise. The intensity of relations between the two fields is divided into different levels. Higher levels of intensity interfere more into the field of earthquake architecture. The given examples interpret various possible levels of cooperation within earthquake architecture.
\end{abstract}

Keywords: earthquake architecture, earthquake engineering, architecture, structures in architecture, building, earthquake resistant design.

\section{Introduction}

In the paper, the expression "earthquake architecture" is used to refer to a particular type of architecture which arises in earthquake prone areas, as a response to the requirements of earthquake engineering and is a consequence of combining earthquake engineering and architecture. The realization of a building without a suitable earthquake resistant structure is not possible today, however, it is possible to design a building in such a way that earthquake resistance is not expressed and structural influence on architecture is minimal. In such cases we 
can speak of concealed ways of earthquake resistance of a building. On the other hand, architecture can respond in the concept itself, i.e. in two ways: effectively, with increased horizontal stiffness of a building or (in addition to that) symbolically, with metaphorical changes in design. Earthquake architecture is the "missing link" between earthquake engineering and architecture. It combines the best of both fields and establishes a new approach and quality in construction in earthquake prone areas, mainly in compliance with measures of architectural excellence.

The complex requirements of earthquake engineering directly influence the architectural composition and concepts in architecture, thus detailed examination of influences is the basis for any architectural activity in seismic areas. The modern methods for increasing earthquake resistance of buildings are based on the seismic codes, as well as on the usage of passive and/or active systems for damping and dissipation of earthquake energy. According to (Mezzi et al [9]) they enable a freer building design and more flexible solutions in architectural design in earthquake prone areas.

It has been noted that, by introducing more and more detailed standards and regulations, the principles of earthquake resistant design are becoming important determining factors of architectural design in earthquake prone areas. It seems reasonable to believe that architecture should always be local, i.e. designed in accordance with micro-location features of the area, and that it should in some way respond to the earthquake threat. Adjustment to the earthquake resistant construction requirements is often regarded as pressure on artistic freedom and a limitation in following trends coming from the areas of the developed world not prone to earthquakes (the Netherlands, Great Britain, Scandinavia, etc.). But the problem in question is not the limitations, but rather lack of knowledge and inability to develop a particular and, within frameworks of earthquake resistant construction, inventive architecture.

Our hypothesis is that, at the contemporary time of emphasised concern for sustainable and regional development and in searching for a new, particular expression in architecture, the response of architecture to earthquake threats can present an important source of stronger architectural identity typical of earthquake prone regions. In the paper the hypothesis is verified by a comparative analysis and intersection of concepts of modern earthquake resistant design and architectural concepts of composition and building design. Furthermore, the article analyses the basic characteristics of earthquake architecture and seeks and examines the areas of possible conflicts and constraints.

\section{Concepts of modern earthquake resistant design}

When designing a building in a seismic area, we have to comply with the regulations and recommendations given in building standards and codes. These demands have a decisive influence on the design of structural system of the object, which in turn interferes with the architectural concept. Earthquake engineering has developed a variety of ways for increasing earthquake resistance of buildings, 
which present different concepts of building protection in line with generally established design philosophy in earthquake prone areas. Roughly, the ways of achieving suitable earthquake resistance of a building can be divided into the following four groups: A) tectonic construction, B) basic protection according to regulations, C) passive protection, D) active protection and developing systems.

\section{A) Tectonic construction (regularity, symmetry, height limitation, etc.)}

Classic, tectonic (also traditional) principles of regular construction are taken into consideration, which were in force in history before the establishment of building codes: mass is concentrated in the lower storeys, walls are massive (thick) and are getting thinner towards the top, regularity is ensured (symmetry, direct supporting, maximum floor plan dimension ratio 1:4), buildings have height limitations which depend on the materials used, layout shows high density of structure which warranties the shear transmission of horizontal forces into foundations. The structure is "designed" to remain elastic during a potential earthquake. In our case this term refers to emphasised and prevailing principles of regular construction. Examples of markedly non-tectonic construction are buildings with a soft ground floor, with the majority of mass in the upper floors, irregularly shaped, with larger overhangs, etc.

\section{B) Basic protection according to codes (modern earthquake resistant construction, required combination of strength and ductility)}

The basic protection according to modern building codes developed in the last decades, and as it is defined in this paper, presents nowadays a minimum level of earthquake resistant construction, which has to be taken into account when constructing new buildings and when adapting existing buildings in earthquake prone areas. It has to be emphasised that structural engineer, in contrast to an architect, is held liable for the adequacy of a structure design, which means that all systems used must comply with code requirements for safety and quality.

\section{C) Passive protection (base isolation, energy dissipation systems)}

This group includes various passive base isolation systems, which are usually combined with various types of passive energy dissipation systems or devices. These structural protective devices can be divided into two major groups: 1) Seismic isolation (elastometric or lead rubber bearings, sliding friction pendulum bearings and sliding bearings with restoring force) and 2) Damping systems (histeretical dampers, viscous dampers, tuned mass/liquid dampers, phase transformation dampers) (Constantinou et al [5]). These systems can be placed above the foundations or in critical areas along the entire structure.

\section{D) Active protection (base isolation + semi-active and active damping systems) and systems in development}

This is an upgrade to passive protection, which includes the use of the latest technologies, such as semi-active and active energy dissipation systems (mass/fluid dampers, bracing systems etc.), computer controlled response of buildings to earthquake simulation using electrorheological (ER) and magnetorheological (MR) dampers and other smart variable stiffness and 
damping systems. The material properties of ER and MR materials can be changed in milliseconds by an applied low-power electric, or magnetic, field. At zero electric field, these materials are viscous liquids. At high fields they behave like viscoelastic-plastic solids. Members making use of ER or MR fluids can regulate very large forces with almost no external energy. (Yang [11]). One of the most promising developing technologies today in areas with frequent (regular) seismic activity is Neuro-fuzzy logic systems or Fuzzy systems (also Neural fuzzy models) (Kim et al [7]). It is an active, computer controlled system, which monitors earthquake activity in the location itself, and treats the building and its surroundings as a complex dynamic system. After processing information, it can in this way calculate the highest probability of earthquake direction and automatically "prepares" for an earthquake. After several earthquakes, the computer as a neuron network uses the "fuzzy logic" principle to predict the next earthquake. Neuro-fuzzy logic system enables a certain form of local seismic predictions, which are though to be the most accurate for the building in question, and is related to (semi-)active protection systems.

\section{Concepts of architectural composition and design}

Architectural composition and concepts have not changed much from antique, when first architectural theorist Vitruvius determined architecture by structure (firmitas), usefulness (utilitas) and aesthetics (venustas). Studying the architectural theory, we find these postulates in various forms throughout all history and it seems they have remained unchanged from their formation until today. Despite the differences in interpretation, none of the more serious definitions questions the status of architecture as art. The work of an architect has the characteristics of a cultural act and artistic achievement. With the development of architectural theory, the previously mentioned postulates have been complemented by numerous other detailed starting points and subdivisions, among which we most frequently come across spatial (urban) aspects, which are actually a matter of context. Architectural concepts, which arise through evaluation and ethics, are nowadays determined also by: location and urbanisation of the environment, the morphology of a building and its surroundings, context, the significance of an building with regard to purpose and/or importance, historical determination, building typology, the concept of architectural design, the elements of architectural design, the harmony of composition (ratios, relations) and other starting points, about which an architects forms an opinion, assesses the existing situation and carries out architectural intervention in the space. In doing so, the architect takes full responsibility for the space, which can be upgraded, neutralized, or deformed etc. by his intervention.

Thus architecture is not an idealised form, but a consequence of starting points offered by the site, when it is evaluated, read and analysed in the process of creation, and which, after all, represents the prevailing category for determining architecture. Structure and in our case earthquake design of a building is the necessity which ensures safety and stability of a building. Modern construction and earthquake engineering enables much more than in the past; therefore the need for architectural freedom has increased as well, and should be more accessible with the help of technology. 
Architecture is perceived in different ways. It comprises the visual aspects of a building in space and the abstract perception of architecture not visible to the eye, but which can be comprehended through the use and sensual perception of the building. Regarding visual effects, the earthquake resistant load bearing structure can be emphasised or hidden and concealed. In his article A postbiblical view Lebbeus Woods clearly emphasises the importance of adequate construction in seismic areas: "Earthquakes as natural event are not inherently catastrophic. Destruction is not the 'fault' of earthquakes, but rather of the buildings, which, even in the regions regularly visited by earthquake, are not designed to work harmoniously with the violent forces periodically released." (Woods in: Garcia [16]). It is this ability to harmonize the actual (structural) and architectural (aesthetic) response to earthquake forces which we ought to be searching for and appreciate in assessment.

\section{Earthquake architecture}

\subsection{Definition}

The broad expanse of the intersection of architecture with earthquake engineering is considered to be within the scope of the term earthquake architecture. The first mention of the phrase earthquake architecture occurs in the paper "Earthquake Engineering and Earthquake architecture" by Bob K. Reithermann. He noted that while 'earthquake engineering' was a common term for organisations and conferences, 'earthquake architecture' had an unaccustomed ring to it, and asked "Is there such a thing as earthquake architecture, and if so, what is it?" (Reitherman [10]). C. Arnold uses the phrase earthquake architecture to describe a degree of architectural expression of some aspect of earthquake action or resistance (Arnold [2]). The breadth of expressive possibilities ranges from metaphorical (visually expressed) uses of seismic issues, to the more straightforward exposure of seismic technology.

Nunotani Headquarter Building in Tokyo (Figure 1) is an extreme example of metaphor and symbolism used in an architectural response to seismic design. Its disjointed and displaced facade elements are intended to "represent a metaphor for the waves of movement as earthquake periodically compress and expand the plate structure of the region." However, the fact remains that seismic issues have generated an innovative architectural design concept (Charleson and Taylor [3]).

\subsection{How to achieve earthquake architecture?}

Earthquake architecture can be defined as any visual or conceptual interconnection between the concepts of earthquake engineering (section 2) and concepts of architecture (section 3). The inclusion of the requirements of earthquake resistant design in the process of creating and conceptualizing the architecture of a real building can be based on conceptual or visual level. Looking at it visually, we can speak of hidden and concealed ways of earthquake resistant architecture on the one hand, and revealed or emphasised on the other. From the conceptual point of view, earthquake architecture is realized only by 
including the principles of earthquake engineering in the architectural concept itself, and in this way we achieve the highest level of cooperation through identification, where architecture is based entirely on the principles of earthquake engineering. Strategies for realizing the vision of a more widely accepted earthquake architectural approach inevitably depend on architects. Structural engineers need to be the catalysts for the vision to be caught and progressed (Charleson et al [4]). In the present paper, which presents the first steps of our research, we decided to analyse three different levels of including earthquake engineering in architecture:

Level 1: Earthquake resistance as a concept is inferior to architecture;

Level 2: Concepts of architecture and earthquake engineering are complementary;

Level 3: Earthquake resistant structure identifies architecture.
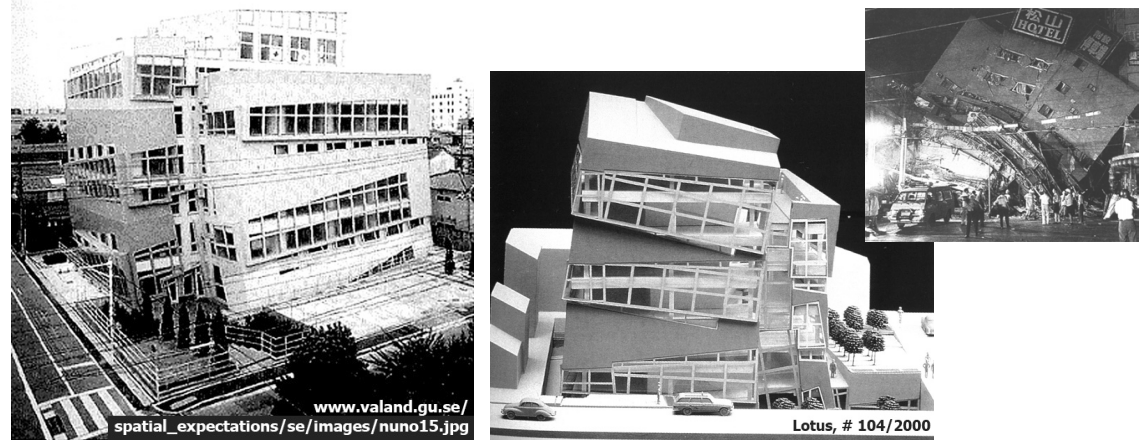

Figure 1: Example of symbolism and metaphor which architecture uses to react to earthquake threats: Nunotani Headquarter Building in Tokyo.

We have noted that there is not much earthquake architecture in earthquake prone areas. We can claim that a large number of buildings do not show architectural, i.e. visible or conceptual characteristics of earthquake architecture, or they use merely hidden ways of earthquake safe construction and earthquake engineering technology. In these cases the possibility of using earthquake architecture as a form of expression thus remains unrealized potential. Nonetheless, there is also a negative side to earthquake architecture, we might call it "anti-" or "non-earthquake" architecture. In this case the visual and abstract in architecture is achieved by contradicting earthquake reality, which negates (confrontation) or ignores (indifference) the requirements of earthquake design. At the worst, architecture can defy the rules of earthquake resistant construction with intentional mistakes in design. This negative side represents the conflict in the relationship between earthquake engineering and architecture, thus also within earthquake architecture itself. In this case legislation is the only guarantee that "anti-earthquake" architecture cannot be realised to the full extent in practice. 


\subsection{Examples of earthquake architecture}

The three assumed levels of including earthquake engineering in architecture can be supported with the following examples.

\section{Level 1: Earthquake resistance as a concept is inferior to architecture}

The expressiveness of architecture is above structure, which as an inferior partner mainly provides safety and serves the architectural concept, which actually does not originate in earthquake design. An already conceptualized building, sometimes together with the structure, seeks confirmation in earthquake engineering and adapts minimally to the requirements of earthquake safety in further procedures. Advanced technologies can be used, structure is hidden behind facades and majority details are hidden. Two such examples are shown in Figure 2. Architecture achieves a high level of autonomy, sometimes at the expense of earthquake resistance of a structure. The influence of structure on architecture is thus minimal and mostly has an inferior role.
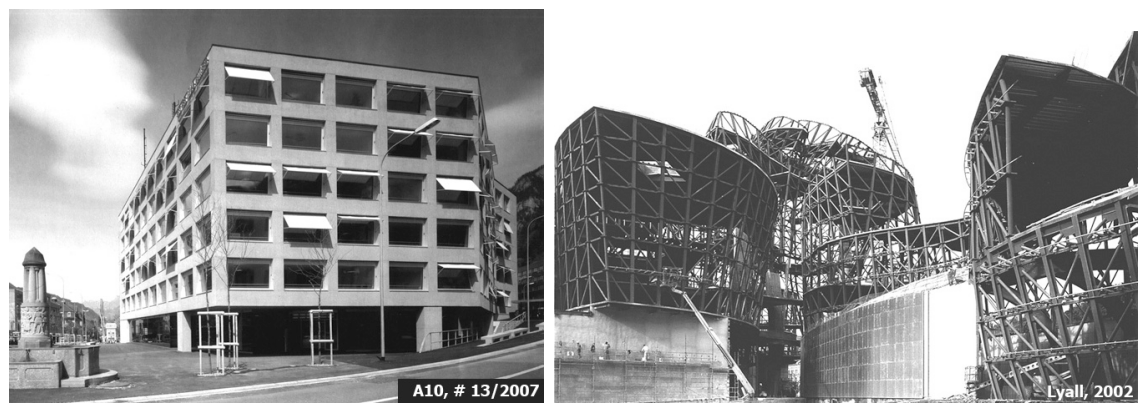

Figure 2: Structure adapted to the requirements of architecture: a building with "soft storey" (left) and the structure of a museum in Bilbao which simply follows the architectural idea which is completely formalistic and artistic. In the end, the entire structure is covered with façade (right).

\section{Level 2: Concepts of architecture and earthquake engineering are complementary}

Structure design is expressed and visible in the facades of buildings and the interior. Structure design is one of the motives of architecture and is also a logical consequence of building design. In this instance a high level of cooperation of both fields and mutual understanding are needed. The influence on architecture can be substantial; however, it can also be almost invisible or minimal, if it means the integration of structure into architectural design. A few examples where the cooperation between architecture and earthquake engineering was one of the guides in architecture design are presented in Figure 3.

\section{Level 3: Earthquake resistant structure identifies the architecture}

This level is based on using structure as the exclusive aesthetic norm, i.e. structure is the only articulated form which determines architecture. This 
principle could be named (earthquake resistant) structure as architecture and enables a high intensity of development in both earthquake engineering and architecture (Lyall [8]). It is hardly possible to speak of influence on architecture, since this level is all about structure which $i$ s architecture (Figure 4). The author can be an engineer who uses structural design to also give a building its final form, or an architect with detailed knowledge of earthquake engineering, materials and structures.
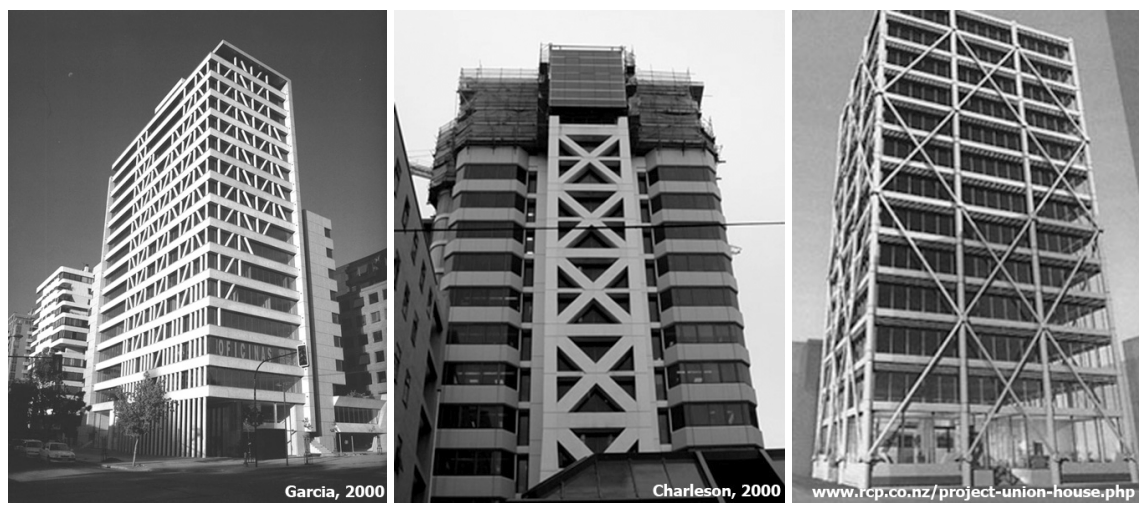

Figure 3: Example of cooperation between architecture and earthquake engineering: Manantiales building, Chile (left), Wool House in Wellington (middle) and Union House in Auckland with added bracings (right).
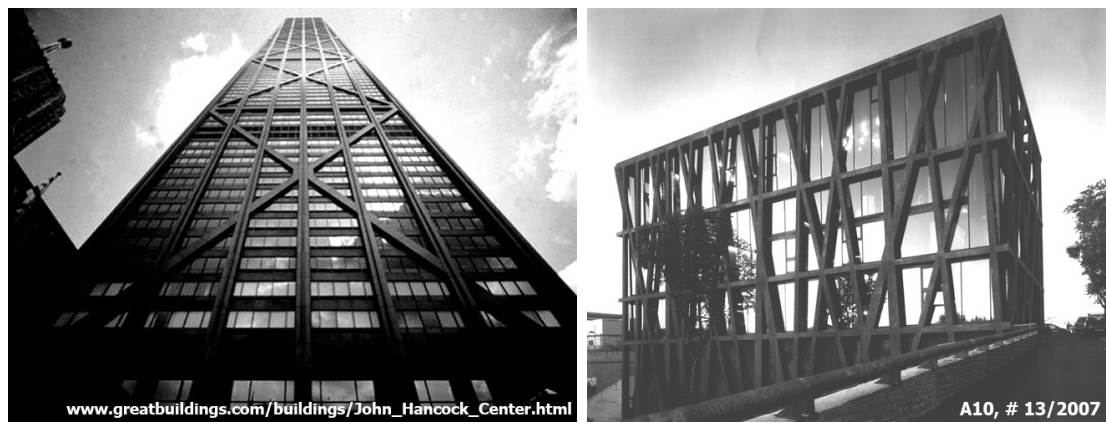

Figure 4: Example of identification of architecture with seismic design: tectonic (trapezoidal) shape of Hancock Building in Chicago with visible bracings over the facade (left) and Dance centre Aix-enProvence (right).

Concepts of earthquake protections in contemporary architecture also derive from ideas of bionics applicable to engineering and architecture. One of the most powerful tools nature has at its disposal to solve resistance problems in live organisms is force microfragmentation (Pioz in: Garcia [6]). The shift from metaphor of the machine to the metaphor of the organism is evident (Abley and Heartfield [1]). The aim of such an approach is to engage in a high level of 
cooperation with engineers or use integral knowledge to design architecture which would be a synthesis of smart materials, form and structure. Some examples are given in Figure 5.
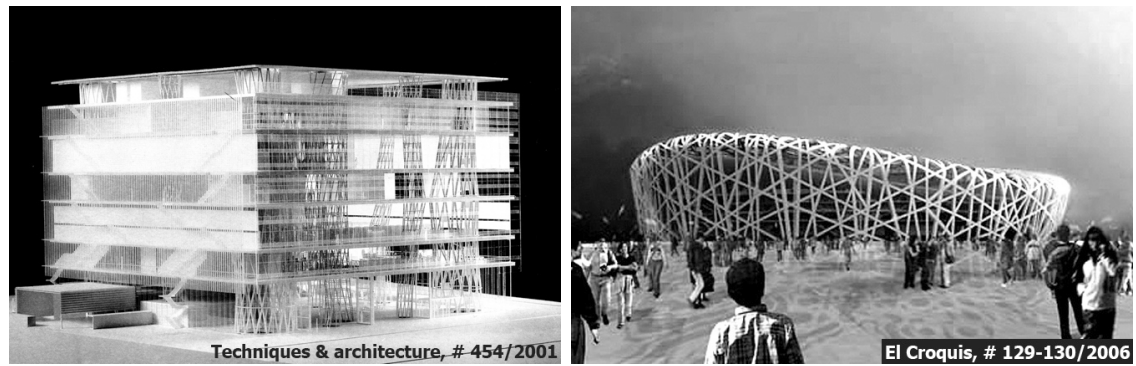

Figure 5: Example of "force microfragmentation": Municipal multi-media library in Sendai and project of the Olympic stadium "Bird's Nest" in China.

There are no clear divisions between the above mentioned levels of relations in earthquake architecture, which means that transitions from one level to another are sometimes possible in the process of architectural work in earthquake areas. With everything considered, it is important to distinguish between the actual effect architectural design has on horizontal resistance of a building and the symbolic or metaphorical reaction as a response of architecture - art to uncontrollable forces of an earthquake, which in some cases, due to irregularity and the desire to "provoke", even causes weaknesses or conscious structural mistakes. In this case we speak of a negative version of relationship within earthquake architecture.

\section{Conclusions}

From the first preliminary results of review, analysis and evaluation of earthquake architecture we can make the following observations and conclusions:

- The response of architecture to earthquake threats can present an important source of a stronger architectural identity typical of earthquake prone regions.

- Earthquake architecture can be defined as any visual or conceptual interconnection between the concepts of earthquake engineering and concepts of architecture.

- Looking at it visually, we can speak of hidden and concealed ways of earthquake resistant architecture on the one hand, and revealed or emphasised on the other. From the conceptual point of view, earthquake architecture is realized only by including the principles of earthquake engineering in the architectural concept itself.

- There is not much earthquake architecture in earthquake prone areas. Thus the possibility of using earthquake architecture as a form of expression remains unrealized potential. 
- "Anti-" or "non-earthquake" architecture contradicts the earthquake reality by negation (confrontation) or ignorance (indifference) of the requirements of earthquake design. In this case the building code is the only tool that can prevent "anti-earthquake" architecture to be realised to the full extent in practice.

- Earthquake architecture is the "missing link" between earthquake engineering and architecture. It combines the best of both fields and establishes a new approach and quality in construction in earthquake prone areas, mainly in compliance with measures of architectural excellence.

- Further research and analyses of interconnections of architectural and earthquake resistant concepts within the field of earthquake architecture are planned to be conducted in the near future.

\section{References}

[1] Abley, I., Heartfield, J., 2001: Sustaining architecture in the anti-machine age. Wiley-Academy, John Wiley \& Sons Ltd. London.

[2] Arnold, C., 1996: Architectural aspects of Seismic Resistant Design. Proceedings of the 11th World Conference on Earthquake Engineering.

[3] Charleson, A.W., Taylor M., 2000: Towards an Earthquake Architecture, Proceedings 12th WCEE, NZ National Society for Earthquake Engineering.

[4] Charleson, A.W., Taylor, M., Preston, J., 2001: Envisioning Earthquake Architecture in New Zealand, Proceedings of the Technical Conference of the New Zealand Society for Earthquake Engineering Annual Conference, Wairakei.

[5] Constantionou, M., Soong, T. T., Dargush, G. F., 1998: Passive Energy dissipation systems for structural design and retrofit. MCEER, University of Buffalo, NY, USA.

[6] Garcia, B., 2000: Earthquake Architecture, New construction techniques for earthquake disaster prevention. Loft Publications, Barcelona.

[7] Kim, H., Roschke, P. N., Lin, P., Loh, C., 2005: Neuro-fuzzy model of hybrid semi-active base isolation system with FPS bearings and an MR damper. Science direct.

[8] Lyall, S., 2002: Masters of Structure, Engineering Today's Innovative Buildings. Laurence King Publishing Ltd, London.

[9] Mezzi, M., Parducci, A. and Verducci, P., 2004: Architectural and Structural Configurations of Buildings with Innovative Aseismic Syst., Proc. of the 13. WCEE.

[10] Reitherman, R., 1985: Earthquake Engineering and Earthquake Architecture. Part of the AIA "Workshop for Architects and Related Building Professionals" on Designing for Earthquakes in the Western Mountain States.

[11] Yang, G., 2001. Large-scale magnetorheological fluid damper for vibration mitigation: modeling, testing and control. (dissertation) Graduate school of the University of Notre Dame, Indiana. 